\title{
PERANCANGAN SISTEM TANDA DAN INFORMASI MUSEUM/ISTANA LANGKANAE KOTA PALOPO
}

\author{
Askhabul Kahfi Fathoni \\ Desain Komunikasi Visual, Fakultas Seni dan Desain, Universitas Negeri Makassar \\ askhabulk7@gmail.com
}

\begin{abstract}
ABSTRAK
Perancangan ini bertujuan untuk merancang sebuah sistem penanda dan informasi yang informatif, dan memiliki daya tarik visual yang komunikatif dan sederhana untuk membuat para pengunjung objek wisata Istana Kedatuan Luwu Langkanae dapat merasa nyaman selama berwisata. Kumpulan data dalam perancangan diperoleh melalui studi pustaka dengan mencari studi kepustakaan yang terkait, Wawancara kepada pengelola Istana Kedatuan Luwu serta beberapa wisatawan yang sudah pernah berkunjung ke Istana Kedatuan Luwu, Observasi secara langsung di tempat objek penelitian, serta dokumentasi yang dilakukan di sekitaran komplek Istana Kedatuan Luwu serta di dalam Museum. Konsep desain pada perancangan sistem tanda dan informasi Museum/Istana Langkanae ini adalah simple etnik. Simple pada perancangan didefiniskan sebagai kesederhanaan mengarah kepada tujuan pencapaian informasi yang mudah diterima dan dipahami oleh target audiens, sedangkan etnik yang dimaksud ialah tampilan yang memiliki unsur kebudayaan lokal sebagai ciri khas perancangan. Konsep desain simple etnik ini akan menggambarkan kesederhanaan pada desain dengan memasukkan unsur-unsur kebudayaan Luwu didalamnya. Hasil perancangan dalam perancangan kali ini adalah sebuah penanda informasi benda pusaka dalam Museum Batara Guru yang berupa QR Code yang dapat di scan melalui smartphone para pengunjung Museum/Istana Datu Luwu Langkanae.
\end{abstract}

Keywords: Sistem; tanda; informasi; Istana Datu Luwu; Langkanae

\begin{abstract}
This design is aimed to design an informative sign and information system, with communicative and simple visual appeal to make visitors comfortable during their visit. A collection of data in this design was obtained through literature study by searching for related studies. Interviews with the staff of the palace of Kedatuan Luwu and several of visitors who had visited the palace. Direct observation at the object of research, and documentation carried out around the Palace of Kedatuan Luwu and inside of the Museum. The design concept of this Sign and Information System in the Museum/Langkanae Palace is simple ethnic. Simple in this design is defined by a simplicity leading to the object of this information, easily accepted and understood by the target, meanwhile ethnic is the look that has a local culture element as a character of this design. The simple ethnic concept of this design will illustrate simplicity in the design by putting the elements of Luwu cultural into it. The design output, is an information sign of the collection in Museum Batara Guru as a QR Code that will be able to be scanned by smartphone the visitors of Museum/Palace of Datu Luwu Langkanae.
\end{abstract}

Keywords: Sign and Information System, Palace of Datu Luwu, Langkane

\section{PENDAHULUAN}

Tidak salah jika Indonesia sangat kaya akan tempat wisata, mulai dari wisata alam, wisata bahari, hingga wisata bersejarah yang ada di Indonesia. Tidak heran jika sektor pariwisata ini sangat diperhatikan oleh Pemerintah. Menurut Undang-Undang nomor 10 Tahun 2009 tentang Kepariwisataan, yang dimaksud dengan pariwisata adalah 
berbagai macam kegiatan wisata dan didukung berbagai fasilitas serta layanan yang disediakan oleh masyarakat, pengusaha, pemerintah, dan pemerintah daerah. Cahyadi (2009:2)

Di antara beberapa jenis wisata yangada di Indonesia, pariwisata pusaka atau juga yang lebih dikenal dengan pariwisata peninggalan sejarah dan budaya (cultural and heritage tourism ataucultural heritage tourism) adalah salah satu jenis wisata yang menarik bagi wisatawan dalam maupun luar negeri.

Di Indonesia, beberapa macam bentuk objek wisata ini adalah, benteng, pemakaman, masjid, stasiun, sebuah monumen, kanal, dan lain-lain. Secara tidak langsung, objek-objek ini termasuk dalam cagar budaya. Cagar budaya menurut Undang-Undang Republik Indonesia Nomor 11 tahun 2010 Pasal 1 (ayat 1) adalah "warisan budaya yang bersifat kebendaan, berupa benda cagar budaya, bangunan cagar budaya, struktur cagar budaya, dan kawasan cagar budaya baik di darat dan /atau di air yang perlu dilestarikan keberadaannya karena memiliki nilai penting bagi sejarah, ilmu pengetahuan, pendidikan, agama, dan/atau kebudayaan melalui proses penetapan.” Subakti (2016:69).

Jadi, pariwisata pusaka atau pariwisata peninggalan sejarah dan budaya merupakan bentuk pariwisata yang menyatukan kegiatan pendidikan, wisata, pelestarian budaya maupun alam dan aktifitas ekonomi. Pariwisata peninggalan sejarah dan budaya pun memiliki manfaat secara ekonomi, dapat membuka lapangan pekerjaan dan meningkatkan pendapatan penduduk maupun daerah. Secara fisik, dapat mempertahankan bagunan bersejarah dan pusaka budaya/alam, peningkatan infrastruktur, dan meningkatkan upaya-upaya konservasi flora/fauna dan ekosistemnya. Secara sosial, semakin dikenalnya masyarakat di daerah tujuan wisata, meningkatnya upaya-upaya menjaga nilainilai budaya setempat, meningkatkan kebanggaan warga, meningkatkan kesempatan akan pendidikan yang lebih tinggi, dan membantu warga untuk memahami diri sendiri dalam hal siapa mereka, di mana mereka berada serta apa keunikan mereka. Cahyadi (2009:8).

(BPS) Menurut data Badan Pusat Statistik mancanegara ke Indonesia naik 15,21 persen pada Juni 2018 bila dibandingkan dengan Juni 2017. Pada Juni 2018, ada 1,32 juta turis asing ke Indonesia, sementara pada Juni 2017 sebanyak 1,14 juta. Khusus Sulawesi Selatan, Jumlah kunjungan wisatawan mancanegara ke Sulawesi Selatan pada bulan Juni 2018 mencapai 1.216 kunjungan. Angka tersebut naik sebesar $83,96 \%$ jika dibandingkan dengan jumlah wisatawan pada bulan Mei 2018 yang mencapai 661 kunjungan. Namun jika dibandingkan dengan Juni 2017 maka terjadi penurunan sebesar 1,94 persen, berada di angka 1.240 kunjungan. Badan Pusat Statistik Provinsi Sulawesi Selatan (2018:19)

Sulawesi Selatan sendiri memiliki banyak objek wisata mulai dari wisata alam, bahari, hingga Sejarah dan Budaya. Objek wisata sejarah dan budaya khususnya daerah Kota Palopo sangat kental akan sejarah Kerajaan Luwu. Kerajaan Luwu sendiri adalah cikal bakal lahirnya Kota Palopo yang terus berkembang hingga sampai saat ini.

Berbicara mengenai Sulawesi Selatan khususnya, maka sulit untuk tidak mengenang kerajaan Luwu dan tokoh-tokohnya. Sebab dari sinilah, lahir propinsi Sulawesi Selatan kelak. Bahkan termasuk beberapa daerah yang kini tidak berada dalam wilayah Sul-Sel (Luwu), di zaman dahulu termasuk wilayah Sulawesi Selatan (Luwu). Dengan demikian, dapatlah dikatakan bahwa Luwu merupakan akar kebudayaan yang telah berintegrasi dalam wilayah kesadaran masyarakat pendukungnya. Disadari atau tidak, keagungan dan kearifan sejarah dan kebuadayaan Luwu telah menjadi kekuatan tersendiri dalam menyerap dan mentransformasikan berbagai anasir kebudayaan dari luar yang kemudian berintegrasi dalam sebuah harmonisasi kebudayaan (Anwar, 2007)

Peninggalan-peninggalan sejarah Kerajaan Luwu pun masih ada dan menjadi objek wisata yang menarik dengan latar cerita kejayaan kerajaan Luwu pada zaman dulu. Salah satu contoh objek wisata tersebut adalah 
Istana Kedatuan Luwu Langkanae. Sebagai objek wisata, sudah sepatutnya memberikan penggalaman yang baik bagi pengunjungnya baik itu dari segi keamanan maupun segi kenyamanan. Namun kenyataannya di objek wisata Istana Kedatuan Luwu Langkanae di Kota Palopo ini belum bisa memberikan pengalaman nyaman dalam hal kemudahan dan kepraktisan dalam berwisata. Kurangnya penanda dan informasi di lingkugan Istana Kedatuan Luwu Langkanae menjadi salah satu faktor yang membuat kenyamanan dalam berwisata kurang maksimal. Penanda atau sign system seharusnya menjadi salah satu media yang dapat memberikan informasi yang komunikatif, informatif, dan efektif tentang objek wisata tersebut. Berdasarkan pengamatan awal saya, informasi mengenai benda peninggalan sejarahnya hanya diberikan label nama yang terbuat dari kertas dan hanya sekedar di tempel di dekat benda-benda pusaka. Begitu pula dengan papan bicara yang ada disana seperti larangan untuk tidak menyetuh benda pusaka juga terbuat dari kertas. Selain itu, tempat wisata Istana Kedatuan Luwu Langkanae juga kurang akan penanda atau Sign System untuk fasilitas umum seperti toilet dan tempat parkir.

Adapun tujuan dari perancangan ini yaitu merancang sebuah sistem penanda dan informasi yang informatif, dan memiliki daya tarik visual yang komunikatif dan sederhana untuk membuat para pengunjung objek wisata Istana Kedatuan Luwu Langkanae dapat merasa nyaman selama berwisata.

Menurut Gumpita oleh (Ivan \& Alfian, 2016) kebudayaan di Indonesia yang sangat kaya bisa di terapkan sebagai inspirasi dalam perancangan, dengan melakukan adaptasi dari kultur budaya yang dimiliki Indonesia. Hal yang tak boleh dilupakan adalah pengaruh desain grafis dari luar yang ikut membantu dan menjadi adaptasi desain grafis di Indonesia, sehingga proses pembentukan identitas Indonesia tidaklah selalu etnis dan berbau kultur secara kental. Jika melihat perkembangan desain grafis sekarang maka Indonesia harus bisa melebur di dalamnya namun tetap memiliki identitas yang melambangkan bahwa karya desain tersebut berasal dari Indonesia.
Perancangan sign system memiliki bentuk dan visual yang sederhana namun tetap otentik dengan potensi-potensi yang ada seperti yang telah dilakukan oleh (Benina \& Kadek, 2014) terhadap Museum Kretek Kudus. Sign system pada museum tersebut juga memiliki informasi yang disampaikan dengan gaya bahasa deskriptif yaitu menggunakan bahasa Indonesia yang baik dan benar serta disusun secara singkat namun tetap komuniktif ketika dibaca oleh keluarga yang merupakan target segemen dari perancangannya. Keunikan yang lain adalah sign systemnya dirancang menggunakan elemen visual khas yang terinspirasi dari kondisi fisik fasilitasfasilitas dan benda-benda dalam museum.

Pada penelitian relevan lainnya oleh (Hardianti, 2013) megungkapkan masayarakat membutuhkan sebuah media informasi yang tersedia ditempat umum untuk memudahkan mereka mendapatkan informasi yang diinginkan, salah satunya adalah peta.

\section{METODE PENELITIAN}

Metode yang digunakan dalam perancangan ini adalah pendekatan kuantitatif, dengan metode penelitian observasi dan wawancara kepada pengelola Istana Datu Luwu serta beberapa wisatawan yang sudah pernah berkunjung ke Istana Datu Luwu serta melakukan observasi dan dokumentasi secara langsung di tempat objek penelitian Adapun hasil analisis yang didapatkan yaitu: 1. Istana Datu Luwu adalah bukti dari kebesaran Kerajaan Luwu pada dahulu kala. 2. Istana Datu Luwu telah menjadi kebanggan bagi warga Kota palopo serta telah menjadi salah satu tujuan utama destinasi wisatawan. 3. Istana Datu Luwu harusnya bisa lebih baik lagi dalam bentuk pelayanan terkhusus sistem tanda dan informasi agar pengunjung dapat lebih mudah dan nyaman dalam berwisata.

Adapun ruang lingkup dari perancangan sistem penanda dan informasi ini, yaitu: Penanda informasi benda pusaka, peta komplek istana (map), penanda tempat parkir (parking sign) dan penanda toilet (toilet sign) dan batasan dari studi kasus ini yaitu lingkup kompleks Istana Kedatuan Luwu Langkanae. 


\section{Teknik Analisa Data \\ Target Audiens}

1. Geografis

- Negara: Indonesia

- Wilayah: Sulawesi Selatan

- Kota/Kabupaten: Palopo

- Ukuran: Warga Kota Palopo

2. Demografis

- Jenis kelamin: Laki-laki dan perempuan

- Usia: 17-45 Tahun

- Agama: Islam

- Ekonomi: Menengah ke atas

3. Psikografis

Dari segi psikografis dapat dipetakan ke orang- orang yang memiliki gaya hidup yang aktif, suka traveling atau berwisata ke tempat-tempat yang memiliki nilai sejarah atau budaya.

4. Behaviour

Dari segi behaviour, Segmen ini dapat dikatakan orang-orang yang terbuka akan sesuatu. Ditujukan untuk laki-laki maupun perempuan yang memiliki atau ingin mengetahui lebih dalam tentang sejarah dan budaya suatu daerah terutama di daerah Kota Palopo.

\section{HASIL DAN PEMBAHASAN Konsep Desain}

Konsep desain adalah awal mula atau cikal bakal dari terbentuknya sebuah desain seutuhnya. Untuk itu, konsep desain yang diusung pada perancangan sistem tanda dan informasi Museum/Istana Langkanae ini adalah simple etnik. Simple pada perancangan didefiniskan sebagai kesederhanaan mengarah kepada tujuan pencapaian informasi yang mudah diterima dan dipahami oleh target audiens, sedangkan etnik yang dimaksud ialah tampilan yang memiliki unsur kebudayaan lokal sebagai ciri khas perancangan. Konsep desain simple etnik ini akan menggambarkan kesederhanaan pada desain dengan memasukkan unsur-unsur kebudayaan Luwu didalamnya.

(Aristantie, 2011) menyatakan Perancangan Sign System perlu diperhatikan dengan penggunaan betuk ikonik konsumen yang dapat memppersepsikan secara langsung sign yang dilihatnya tanpa harus berpikir panjang. Dengan konsep desain simple etnik ini penggunaan warna dalam perancangan lebih menonjolkan warna-warna yang dominan dalam visual kebudayaan Luwu yaitu warm color, penggunaan materi atau elemen visual berupa corak dan pola/pattern yang lebih banyak mengandung unsur kebudayaan Luwu dengan tata letak yang sederhana, dan juga penggunaan typeface yang sederhana dengan anatomi huruf yang mudah dan jelas dengan tetap memberikan kesan etnik dan mudah dimengerti.

\section{Warna}

Warna adalah element penting dalam sebuah perancangan untuk memperkuat kesan sebuah desain. Warna yang akan ditonjolkan pada perancangan sistem tanda dan informasi Museum/Istana Langkanae Kota Palopo kali ini adalah Merah dan kuning, terinspirasi dari warna Pajung Maejae (Payung Merah) dan Pajung Pullaweng (Payung Kuning). Pajung Maejae dan Pajung Pullaweng merupakan payung kebesaran Kedatuan Luwu. Secaravisual, warna merah dan kuning termasuk warna yang menarik dan mencolok "eye catching". Secara psikologi, warna merah bermakna keberanian dan kekuatan dan warna kuning bermakna optimis, semangat, serta menimbulkan hasrat keingintahuan. Pajung Maejae juga terlihat diterapakan di beberapa lambang-lambang penting seperti lambang Kedatuan Luwu, lambang daerah Kota Palopo, lambang daerah Luwu Utara, dan lambang daerah Luwu Timur sebagai salah satu unsur yang sangat penting melambangkan kekuasaan yang tertinggi di Kedatuan Luwu.
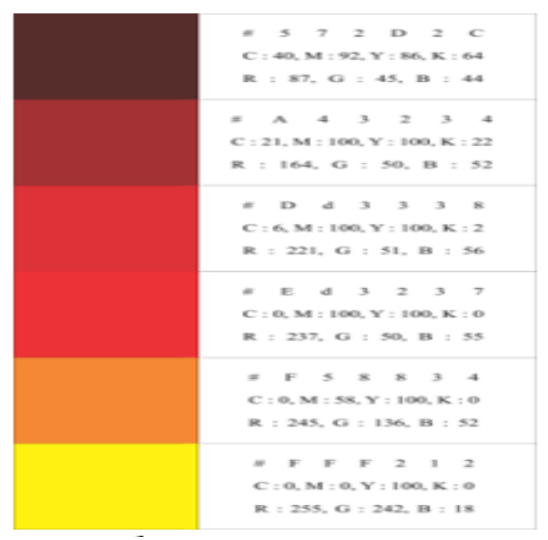

Gambar 1. Warna 


\section{Tipografi}

Dalam perancangan sistem penanda dan informasi di Museum/Istana Kedatuan Luwu akan diciptakan sebuah typeface dengan karakterisitik yang identik dengan Kedatuan Luwu yaitu aksara Lontara yang akan menjadi font utama. Bentuk dari aksara Lontara yang unik dan dapat menjadi sumber inspirasi pembuatan typeface dan dapat mencerminkan image etnik dari konsep desain yang ingin disampaikan serta simple dengan tetap mempertahankan prinsip-prinsip tipografi yaitu legibility (huruf terlihat dan dikenal), clarity (pesan yang disampaikan jelas), visibility (terbaca), readability (mudah dibaca, menarik, dan tidak melelahkan mata). Selain itu, digunakan pula font berjenis Sans Serif untuk menjadi font pendukung pada perancangan kali ini. Font berjenis Sans Serif dipilih karena terlihat simple dan mudah dibaca sesuai dengan konsep desain yang diusung.
UPPERCASE

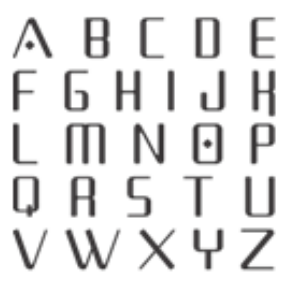

Uppercase

\section{ABCDE \\ FGHIJK \\ LMNOP \\ QRSTU \\ VWXYZ}

LOWERCASE

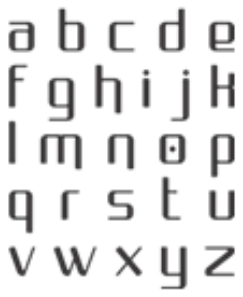

Lowercase

\section{abcde fghijk Imnop qrstu vwXyz}

Gambar 2. Pilihan Font

\section{Sketsa}

Berikut adalah sketsa dari ornament, media Utama dan media pendukung dari perancanagan sistem tanda dan informasi Museum/Istana Langkanae Kota Palopo yang nantinya akan menggunakan perangkat $\mathrm{Qr}$ Code. (Daulay \& Kode, 2015) sendiri menyatakan QR Code dapat digunakan dimana saja setiap saat, memiliki hubungan analog digital dan ketika dibutuhkan dapat dicetak, disamping menjadi hiburan dengan alat pindai kreatif dan ramah lingkungan. QR Code banyak penggunakan di majalah, tempat umum seperti museum, bis dan terminal, ataupun di papan - papan iklan. Namun, walaupun teknologi ini sudah 15 tahun tercipta, di Indonesia kita baru terbiasa dengan "penampakan" kode ini di Harian Kompas belakangan terakhir.

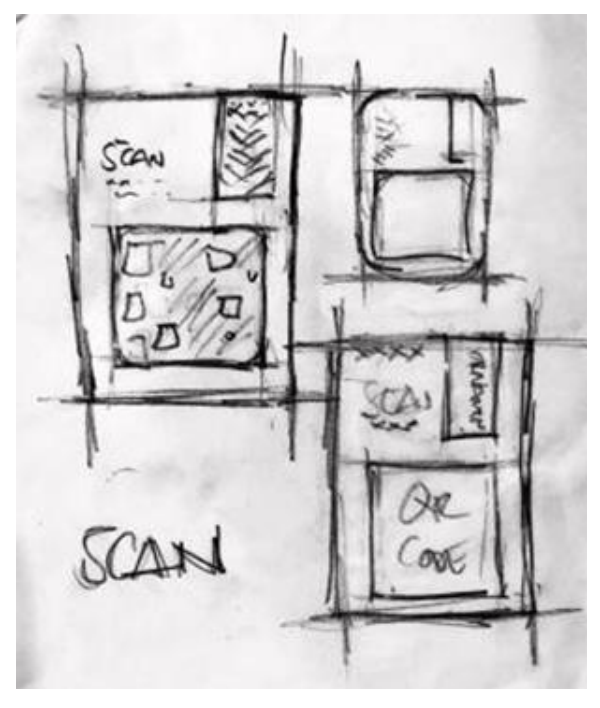

Gambar 3. Sketsa QR Code informasi benda pusaka museum.

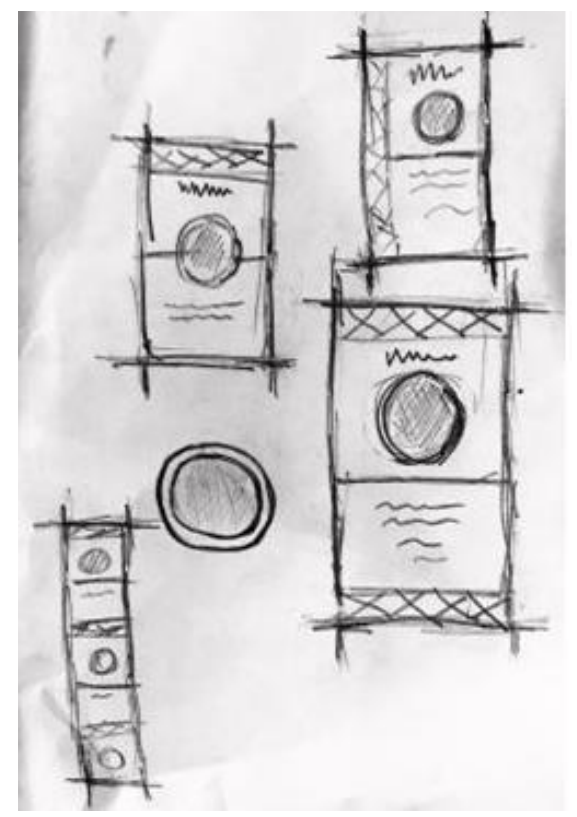

Gambar 4. Sketsa tampilan hasil dari scan QR Code informasi benda pusaka museum 


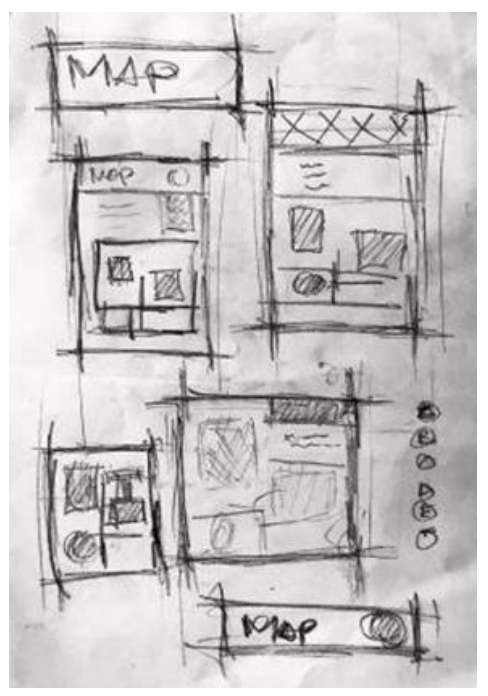

Gambar 5. Sketsa desain map Istana Datu Luwu Langkanae.

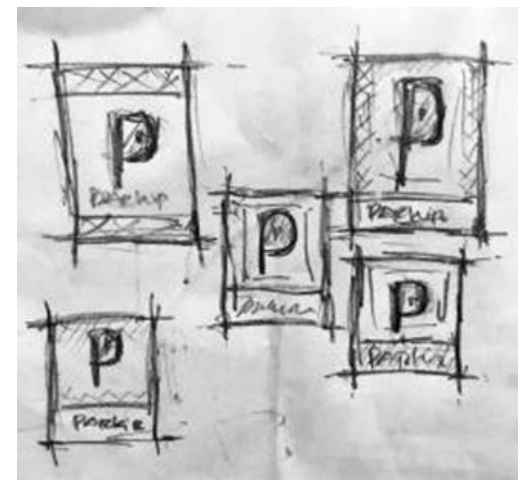

Gambar 6. Sketsa desain parkir sign.

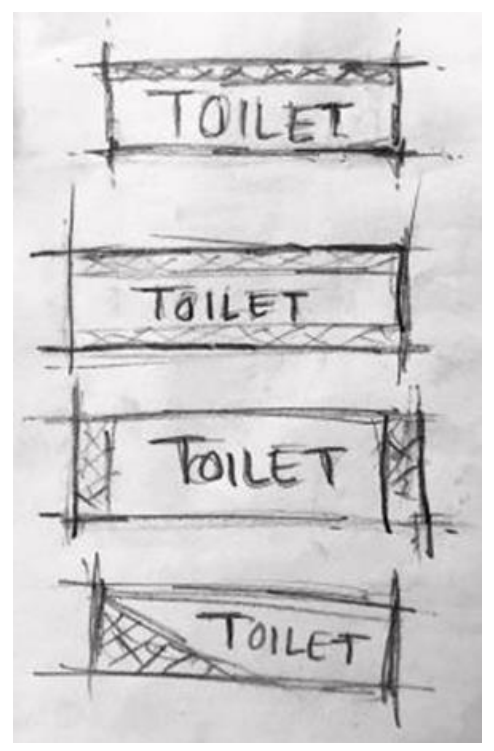

Gambar 7. Sketsa desain toilet sign.

\section{Implementasi Desain}

Dalam proses implementasi desain melewati 2 tahap yaitu, digitalisasi dan perancangan. Dalam proses digitalisasi, seluruh sketsa yang telah dibuat akan diolah kembali dengan teknik digitalisasi menggunakan aplikasi pengolah grafis vektor yaitu CorelDraw X7. Sedangkan tahap perancangan, media utama yang dibuat dalam bentuk digital akan di simpan di website qrcode-generator.com.

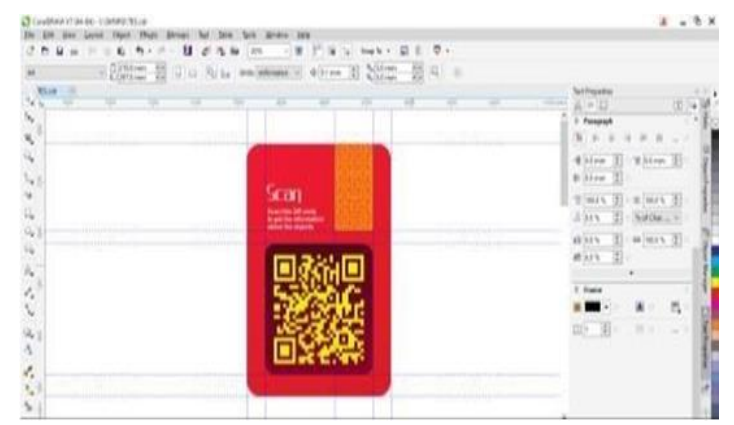

Gambar 8. Proses digitalisasi QR code menggunakan aplikasi CorelDraw X7.

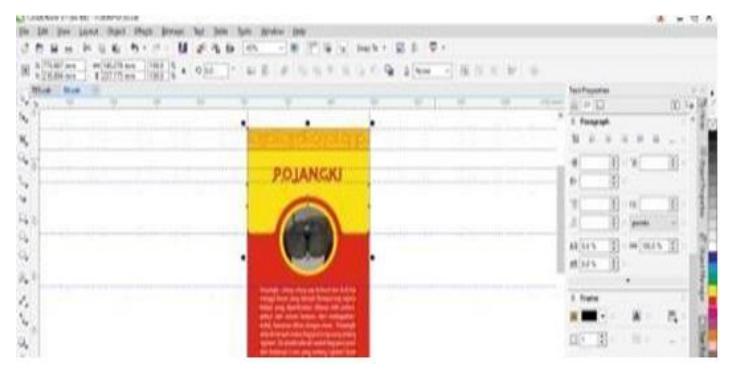

Gambar 9. Proses digitalisasi isi dari QR code menggunakan aplikasi CorelDraw X7.

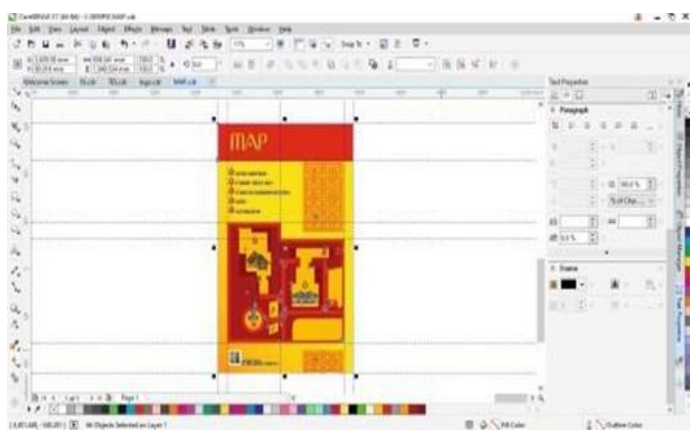

Gambar 10. Proses pembuatan map menggunakan aplikasi CorelDraw X7. 


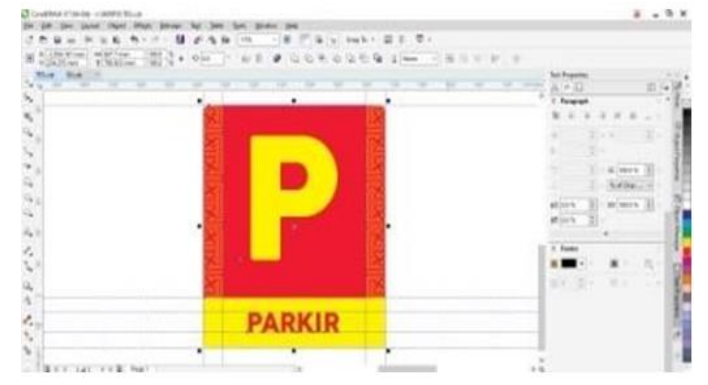

Gambar 11. Proses digitalisasi parkir sign menggunkan aplikasi CorelDraw X7.

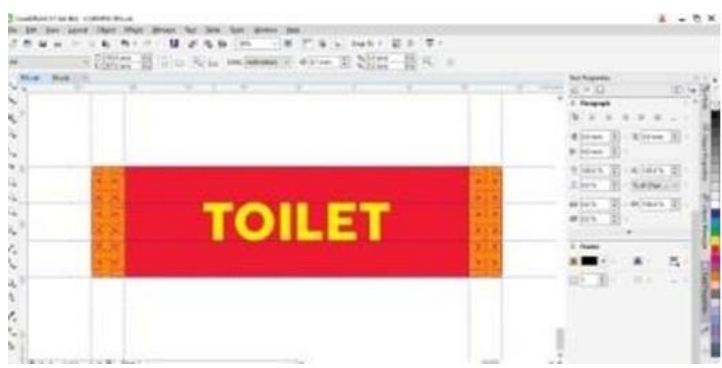

Gambar 12. Proses digitalisasi toilet sign

Hasil dari perancangan ini adalah penanda informasi benda pusaka dalam Museum Batara Guru, dan media pendukung berupa peta komplek Istana Datu Luwu (map), penanda tempat parkir (parking sign) dan penanda toilet (toilet sign).

\section{Media Utama}

Media utama dalam perancangan kali ini adalah sebuah penanda informasi benda pusaka dalam Museum Batara Guru yang berupa QR Code yang dapat di scan melalui smartphone para pengunjung Museum/Istana Datu Luwu Langkanae. Tiap QR code di buat berisi 3 informasi dari benda pusaka yang ada di dalam museum. Ukuran dari QR code yang dibuat adalah $11,7 \times 17 \mathrm{~cm}$ berbahan akrilik dan di cetak dengan teknik digital print. Isi QR Code di sesuaikan dengan layar handphone berukuran $750 \times 1334$ px dengan resolusi 300 Ppi dengan output PNG. Dalam isi QR Code terdapat foto benda pusaka sehingga para pengunjung dapat mengetahui informasi benda pusaka yang di maksud. Ukuran font pada judul informasi benda pusaka adalah 58pt sedangkan ukuran pada isi informasi adalah 16 pt.

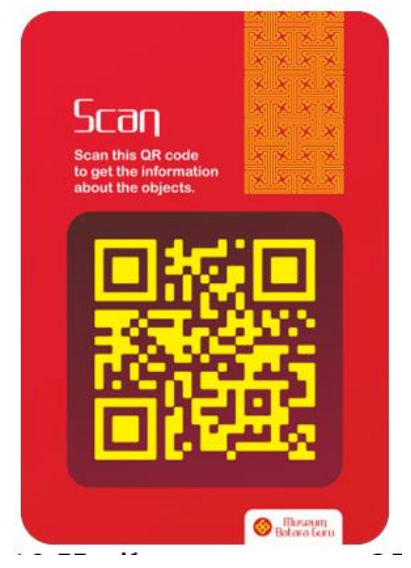

Gambar 13 Hasil perancangan QR code yang berisi informasi tentang benda pusaka dalam Museum Batara Guru.

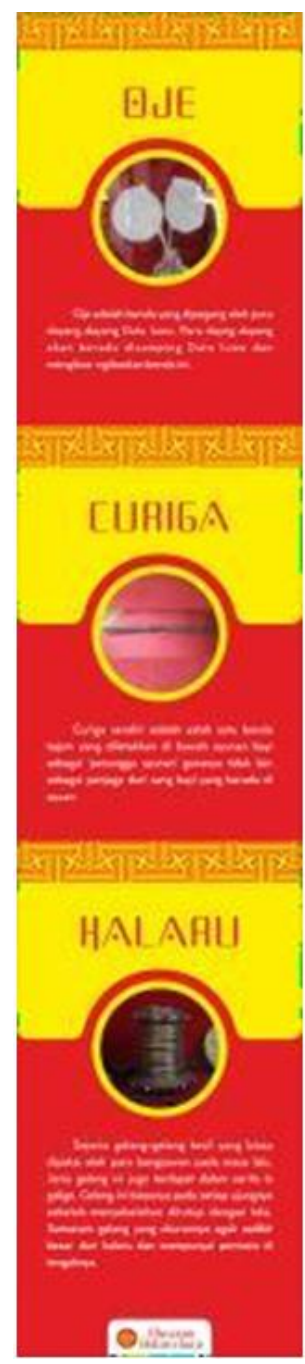

Gambar 14 Hasil perancangan isi dari QR code yang berisi informasi tentang benda pusaka dalam Museum Batara Guru 


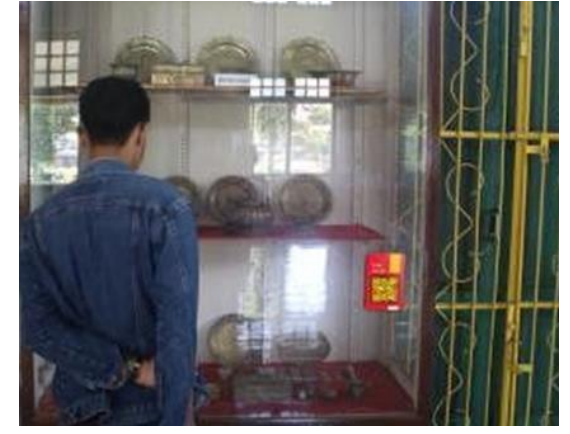

Gambar 15 Mockup QR code yang di pasang di salah satu lemari pajangan benda pusaka Museum Batara Guru.

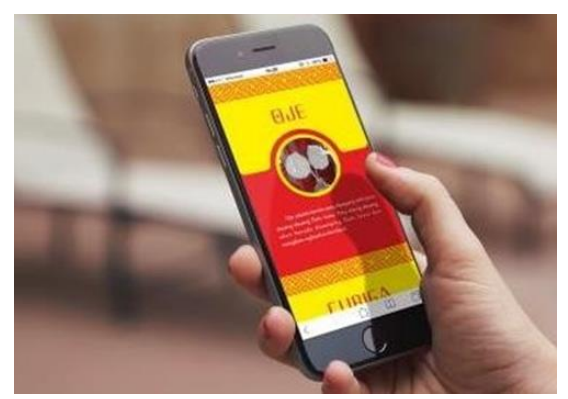

Gambar 16. Mockup isi dari salah satu QR code yang di pasang di salah satu lemari pajangan benda pusaka Museum Batara Guru.

\section{Media Pendukung}

Media pendukung yang dibuat dalam perancangan kali ini bertujuan sebagai pendukung tujuan utama dari perancangan ini yaitu sistem tanda dan informasi di lingkungan Istana/Museum Langkanae.

\section{Map}

Map dibuat sebagai salah satu pendukung dari sistem tanda dan informasi di lingkungan Istana/Museum Langkanae yang bertujuan sebagai pengarah para wisatawan yang berkunjung di lingkungan Istana/Museum Langkanae. Di dalam map terdapat ilustrasi dan keterangan mengenai lokasi dari bangunan-banguan yang ada di dalam komplek Istana Datu Luwu beserta fasilitas umum agar para wisatawan dapat mengetahui lokasi yang ingin dituju dengan mudah. Selain itu, Map yang dibuat juga dapat dipindahi di smartphone para wistawan dengan memindahi QR code yang terdapat di map fisik.

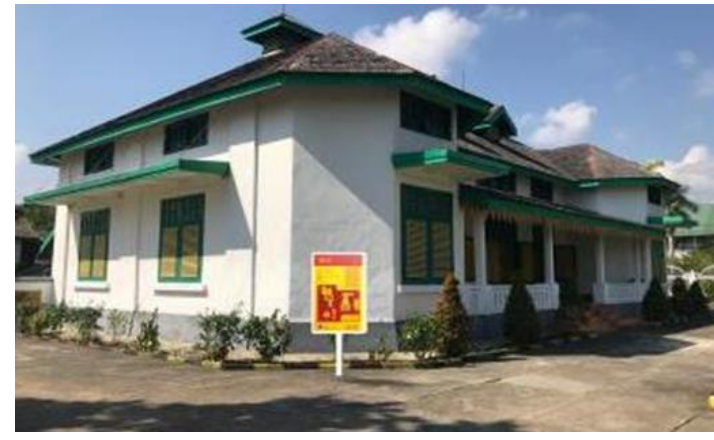

Gambar 3. 16 Mockup map yang terdapat di lingkungan Istana/Museum Langkanae.

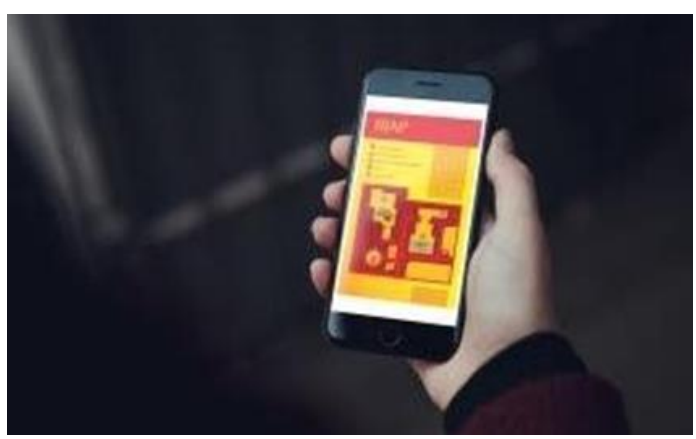

Gambar 3. 17 Mockup map yang di sudah pindahi ke smartphone para wisatawan Istana/Museum Langkanae melalui QR code.

\section{Parkir Sign}

Parkir sign dibuat sebagai salah satu pendukung dari sistem tanda dan informasi di lingkungan Istana/Museum Langkanae yang berfungsi sebagai penanda area tempat parkir kendaraan para wisatawan yang berkunjung ke Istana/Museum Langakane. Parkir sign yang dibuat akan di letakan di 3 titik tempat parkir yang telah tersedia di dalam lingkungan Istana/Museum Langkanae.

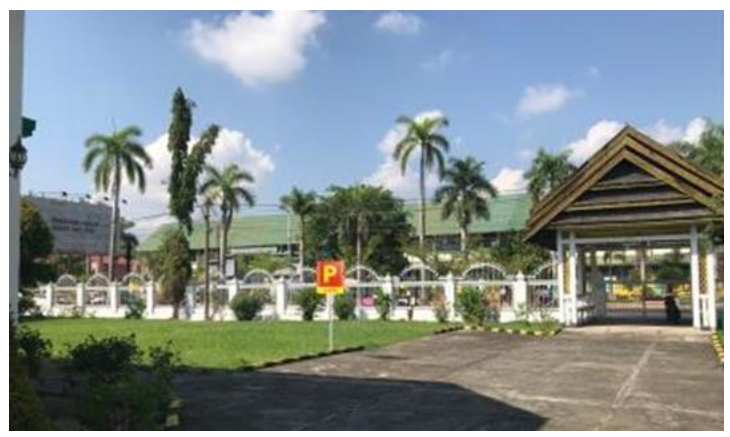

Gambar 3. 18 Mockup parkir sign yang berada di area parkir Istana/Museum Langkanae. 


\section{Toilet Sign}

Toilet sign dibuat sebagai salah satu pendukung dari sistem tanda dan informasi di lingkungan Istana/Museum Langkanae yang berfungsi sebagai penada letak toilet di dalam Istana/Museum Langkanae.

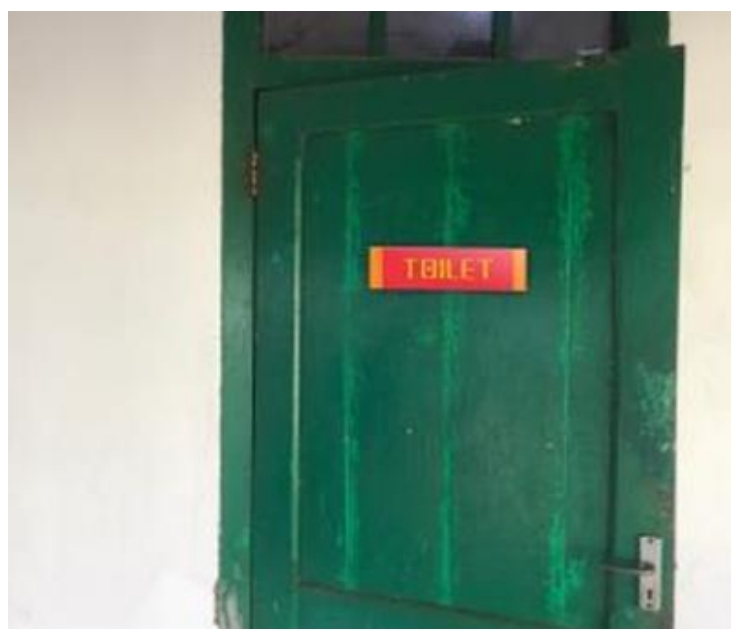

Gambar 3. 19 Mockup toilet sign yang berada di pintu toilet Istana/Museum Langkanae.

\section{KESIMPULAN DAN SARAN Kesimpulan}

Berdasar pada pembahasan hasil kesimpulan yang dapat ditarik yaitu, perancangan sistem tanda dan informasi Museum/Istana Langkanae ini merupakan solusi dari kurangnya sistem penanda dan informasi yang dapat dilihat oleh pengunjung objek wisata Istana Kedatuan Luwu Langkanae selain itu menjadi sistem penanda dan informasi yang informatif, dan memiliki daya tarik visual yang komunikatif dan sederhana untuk membuat para pengunjung objek wisata Istana Kedatuan Luwu Langkanae dapat merasa nyaman selama berwisata. Perancangan ini dirancangan dengan konsep desain simple etnik yaitu deskripsi kesederhanaan pada desain dengan memasukkan unsur-unsur kebudayaan Luwu didalamnya.

\section{Saran}

Dengan adanya sistem tanda dan informasi Museum/Istana Langkanae yang dirancang oleh penulis diharapkan para pengunjung objek wisata Istana Kedatuan Luwu Langkanae dapat merasa nyaman selama berwisata dan pengalaman mengunjungi objek wisata lebih berkesan sehingga objek wisata Istana Kedatuan Luwu dapat lebih eksis dan bertahan lama.

Terlepas dari keterbatasan yang dimiliki, hasil perancangan ini diharapkan dapat memberikan manfaat dan kontribusi untuk penelitian selanjutnya dengan topik serupa. Adapun saran dalam membuat perancangan sistem tanda dan informasi Museum/Istana Langkanae yang dirancang adalah agar tujuan utama perancangan yaitu memberikan kenyamanan kepada pengunjung objek wisata lebih dapat tersampaikan.

\section{DAFTAR PUSTAKA}

Anwar, I. (2007). Ensiklopedi Kebudayaan Luwu. Komunitas Sawerigading.

Aristantie, F. (2011). Perancangan Sign System Taman Satwa Taru Jurug.

Benina, G., \& Kadek, P. (2014). SIGN SYSTEM MUSEUM KRETEK KUDUS. Createvitas: Jurnal Ilmiah Desain Komunikasi Visual, 3(1), 1728.

Badan Pusat Statistik Provinsi Sulawesi Selatan. (2018). Laporan Bulanan Data Sosial Ekonomi Provinsi Sulawesi Selatan Agustus 2018.

Cahyadi, R., \& Gunawijaya, J. (2009). Pariwisata Pusaka (Masa Depan bagi Kita, Alam dan Warisan Budaya Bersama).

Daulay, S. S., \& Kode, Q. R. (2015). Hubungan antara QR Code dan Dunia Industri dan Perdagangan.

Hardianti, T. (2013). Perancangan Peta Rute Operasi Angkutan Kota untuk Wilayah Tangerang Kota. Universitas Multimedia Nusantara.

Ivan, I., \& Alfian, E. (2016). Perancangan Typeface Latin Wicaksana Adaptasi Dari Aksara Jawa. Ultimart: Jurnal Komunikasi Visual, 9(2), 1-7.

Subakti, A. G., Pratomo, A., \& Wiastuti, R. D. (2016). Hotel As Heritage Site Building; From Indonesia Perspective. Umasita, E. (2016). Perancangan Sign System Museum Balla Lompoa. 